Time resolved 3-dimensional recording of redox ratio during spreading depression in gerbil brain.

Quistorff, Bjørn; C. Haselgrove, John; Bashford, C. Lindsey; H. Barlow, Clyde; Chan'ce, Britton; Mayevsky, Avraham

Published in:

Brain Research

Publication date:

1990

Document version

Publisher's PDF, also known as Version of record

Citation for published version (APA):

Quistorff, B., C. Haselgrove, J., Bashford, C. L., H. Barlow, C., Chan'ce, B., \& Mayevsky, A. (1990). Time resolved 3 -dimensional recording of redox ratio during spreading depression in gerbil brain. Brain Research, 506(1), 109-114. 


\title{
Time resolved 3-dimensional recording of redox ratio during spreading depression in Gerbil brain
}

\author{
John C. Haselgrove ${ }^{1}$, C. Lindsey Bashford*, Clyde H. Barlow ${ }^{* *}$, Bjørn Quistorff ${ }^{+}$, \\ Britton Chance and Avraham Mayevsky \\ Johnson Research Foundation, Department of Biochemistry and Biophysics, School of Medicine, University of Pennsylvania, \\ Philadelphia, PA 19104 (U.S.A.)
}

(Accepted 6 Junc 1989)

Key words: Spreading depression; Mitochondria; Redox; Imaging; Spectroscopy; Nicotinamide adenine dinucleotide; Flavoprotein; Fluorescence

Optical fluorescence and reflectance measurcments have becn used to map the distribution of metabolic states in three dimensions in the gerbil brain with a spatial resolution of $200 \mu \mathrm{m}$ and a time resolution of 4-6 s. In Mongolian gerbils anesthetized with pentobarbital, the redox states of the nicotinamide adenine dinucleotide (NADH) and lavoprotein components of the electron transport chain cxhibit two distinet phases during the wave of spreading depression: (1) a transieut period of oxidation and (2) a prolonged period of reduction, during which the cytochromes are reduced, and the hemoglobin is predominantly in the deoxy form. These data are interpreted as indicating that the energy demand placed on the gerbil brain duriug such sprcading depression wave is sufficicnt to drive the brain temporarily hypoxic.

\section{INTRODUCTION}

Spreading depression (SD) of Leao ${ }^{15}$ introduces profound changes in cortical DC potential ${ }^{18}$, membrane potentia $^{6}$, extracellular potassium ${ }^{9,24}$ and blood flow ${ }^{9}$ 18,31,32. These changes spread across the surface of the cerebral cortex at a speed of $2-4 \mathrm{~mm} / \mathrm{min}$ from the site of initiation of SD. Mitochondrial metabolism during spreading depression has been followed by monitoring optical signals from different components of the respiratory $\operatorname{chain}^{20,24,29}$, showing activation of the ATP utilization. Using the terminology of Chance and Williams ${ }^{5}$ this represents a state 4-3 transition. Indeed, increased glucose metabolism ${ }^{8.30}$ has been shown to occur during $\mathrm{SD}$. Nonetheless, there is considerable evidence which suggests that SD is accompanied by anaerobic glycolysis: increased lactate, decreased $\mathrm{pH}$, and increased glucose consumption $7,8,12,30$. Anaerobic glycolysis represents state 5 of mitochondria.

Previous techniques used for following cerebral energy metabolism are restricted in either their spatial or temporal resolution. Optical measurements in vivo can be recorded in two dimensions bnt are restricted to the surface of the brain. Glucose uptake measurements have excellent spatial resolution (of the order of a few microns) but have usually required a 45 min uptake time ${ }^{30}$ causing the transient signals to be minimized. Lactate measurements can be recorded from selected volumes of the order of $0.4 \times 0.4 \times 1.0 \mathrm{~mm}^{13}$. Recent developments in the instrumentation for optical measurement ${ }^{28}$ now allow us to examine the 3-dimensional distribution of mitochondrial redox states throughout brain which have been freeze-trapped ${ }^{27}$ during the propagation of a wave of spreading depression. The present study constitutes a spatial analysis of the various phases of the freeze-trapped SD wave in terms of mitochondrial redox state. Since the speed of progression of the $\mathrm{SD}$ is measured, the spatial analysis also serves as a temporal analysis of the $\mathrm{SD}$ wave.

\section{METHODS}

\section{Animals}

Male adult Mungolian gerbils (60-80 g) from Tumblebrouk farms (MA, U.S.A.) werc anesthetized by an intraperitoneal injection of pentobarbital $(30 \mathrm{mg} / \mathrm{kg}$ ) and mounted to a head-holder. The animals were not paralyzed or ventilated. The skull was exposed, and a $3 \mathrm{~mm}$ diameter region of the parietal bone of oue hernisphere was removed exposing the dura. About 30 min elapsed between the time the animals were anesthetized and the initiation of a single eycle of an SD, which was elicitcd by one of two methods. (i) The brain was injured mechanically by inserting a 27 gauge needle $(<0.4$ $\mathrm{mm}$ diameter) $2 \mathrm{~mm}$ into the brain. There was no bleeding byond the borc made by the needle. (ii) A drop of $0.5 \mathrm{M} \mathrm{KCl}$ saline solution was applied epidurally to the exposed surface of the brain.

Prcsent addresses: *Department of Biochemistry, St. George's Hospital Mcdieal School, London SW 17 ORE, U.K.; **Evergreen State College, Olympia, Washington 98505, U.S.A.; 'Department of Biochemistry, University of Copenhagen, Denmark; ${ }^{+}$Department of Life Sciences, Bar Ilan University, Isracl.

Correspondence: J.C. Haselgrove. Present address: MRI Department, Skejby Hospital, Brendstrupgårdsvej, 8200 Aarhus N, Denmark: 
Inscrtion of the needle initiates SD along a column through the cortex; if the insertion was dccp, it would also initiate SD in deeper parts of the brain (see Results). The application of $\mathrm{KCl}$ initiated SD from a small area at the surface. There was no other observable difference in the results of thesc two mcthods. The metabolism of the brain was arrestcd by "funnel freezing ${ }^{27}$ "at a given time (10 $\mathrm{s}$ to $60 \mathrm{~min}$ ) after the initiation of the SD. Funnel freczing avoids ischemic artefaets bccause the blood supply to the lower nnfrozen regions of the brain continues until frozen at the same time as the metabolism. A funnel with an opening $15-20 \mathrm{~mm}$ wide was placed over the exposed skull, the junetion sealed with vaseline, and liqnid nitrogen poured into the funnel. Freezing was continued for about $30-60 \mathrm{~s}$, during which timc the animal continued breathing. When breathing stoppcd, the whole aninal was immersed in liquid nitrogen. The frozen animal was deeapitated, and the head mounted in the 3-D scanning instrument ${ }^{28}$.

\section{Fluorescence measurements}

The mitochondrial redox state of the tissne was mcasured using a low-temperature scanning fluorometcr. Light from a mereury arc source passes through a filter (altcrnately 366 and $450 \mathrm{~nm}$ ) and is guided onto the surface of the brain by a light gnide. The emitted light is pieked up by a second arm of the light guide and guided through a filter (alternately 450 and $550 \mathrm{~nm}$ ) to a photomultiplier. The experimental and thcoretical principles of this technique have becn described in detail iu earlier papers ${ }^{4.28}$. The metabolic statc of the frozen brain was studied by recording fluorescence of signals from intrinsic fluorochromcs. The two signals were: (i) NADH, which, when excited at a wavelength of $366 \mathrm{~nm}$ cmits light with a peak intensity of abont $450 \mathrm{~nm}$. The intensity of the fluorescence from the reduccd form of the nneleotide, NADH, is correlated to the redox state of the mitochondria. We call this the pyridine nucleotide fluorescence (PN). The oxidized form, NAD, has little absorption or fluoreseence at those wavelengths. (ii) Flavoproteins. when exeited with light of $460 \mathrm{~nm}$ fluoresce with a peak intensity near $540 \mathrm{~nm}$. In contrast to the NAD-NADH fluorescence, the flavoproteins fluoresce more strongly in the oxidized form. We call this the flavoprotein fluorescence (FP).

For fluorescence measurements such as these in which the light is scattered and then re-emitted from the incident surface there is no uniquely defined light path. Wc do not therefore attempt to measure an absolute yaluc for the huorescence efficiency. Instead, we study the distribution of relative fluorescence across the tissue, which we record as the dimensionlcss digitized output of the photomultiplier.

As mcasurcd in the present experiments, the fluorescent signals originatc mainly from the mitochondria ${ }^{11,26}$. Regions of the tissue in which the mitochondrial clectron-transport chain are oxidized will have increased flavoprotein huorescence (FP) and decreased NADH fluorescence (PN) ${ }^{20}$. However, the fluorescent signals will also he governed by the concentration of mitochondria (and hence of the enzymes), and will bc affccted by local blood concentration and oxygenation state since the fluorescent signals arc absorbed strongly by hemoglobin. Such hemoglobin and mitochondrial concentration-related changes will be sinnilar for both the NADH and flavoprotein signals, so the ratio of these two signals at each point of the tissue provides a measnre of the redox state which is relalively independent of local mitochondrial, and hemoglohin conecntrations ${ }^{4}$. We used a modified form of this ratio $M R=$ $\mathrm{FP} /(\mathrm{FP}+\mathrm{PN})$ chosen to kecp the ratio within known bounds $(0-1.0)$.

The distribution of Muorescence signals in 3 dimensions throughout the brain was recorded using an on line scanner to scan a series of planes at different depths through the brain. Successive surfaces werc gencrated by grinding away the previous surface of the frozen brain. Typically, the scan of cach plane consists of an array of $80 x$ 80 points, $200 \mu \mathrm{m}$ apart. Each ineasurement represents a volnme of tissuc about $120^{\circ} \times 120 \mu \mathrm{m}$ in the plane of the surface and $50 \mu \mathrm{m}$ deep. In all the images we show here we use our usual convention that the high signals are displayed white and the low ones dark.

\section{Scanning reflectance spectroscopy}

Reflectance spectra of the $500-650 \mathrm{~nm}$ region of specific regions on the freeze-trapped brains were made using a Johnson Foundation double beam spectrophotoneter ${ }^{3}$ modified to record rchectance sprectra, as described hy Bashford at al. ${ }^{1}$.

\section{RESULTS}

\section{Spatial distribution of milochondrial fluorescence}

Fig. I shows the FP, PN and MR fluorescence distributions in a typical horizontal section through a brain frozen $35 \mathrm{~s}$ after the initiation of SD with $\mathrm{KCl}$. The dominant feature is the circular region about $6 \mathrm{~mm}$ in diameter in the right hemisphere exhibiting decreased flayoprotein signal, increased NADH (PN), and decreased ratio. All these changes indicate that the mitochondria in this region are reduced.

The maximum extent of the reduction of FP and PN during the reduced period of SD was compared to that in the frozen cortex of control and completely ischemic gerbils. At the point of maximum reduction during SD, the FP signal decreased by $24 \pm 5 \%$ (mean \pm S.D.) while the PN signal increased $74 \pm 20 \%$ the ratio MR decreased hy $40 \pm 6 \%$. Within experimental error, these

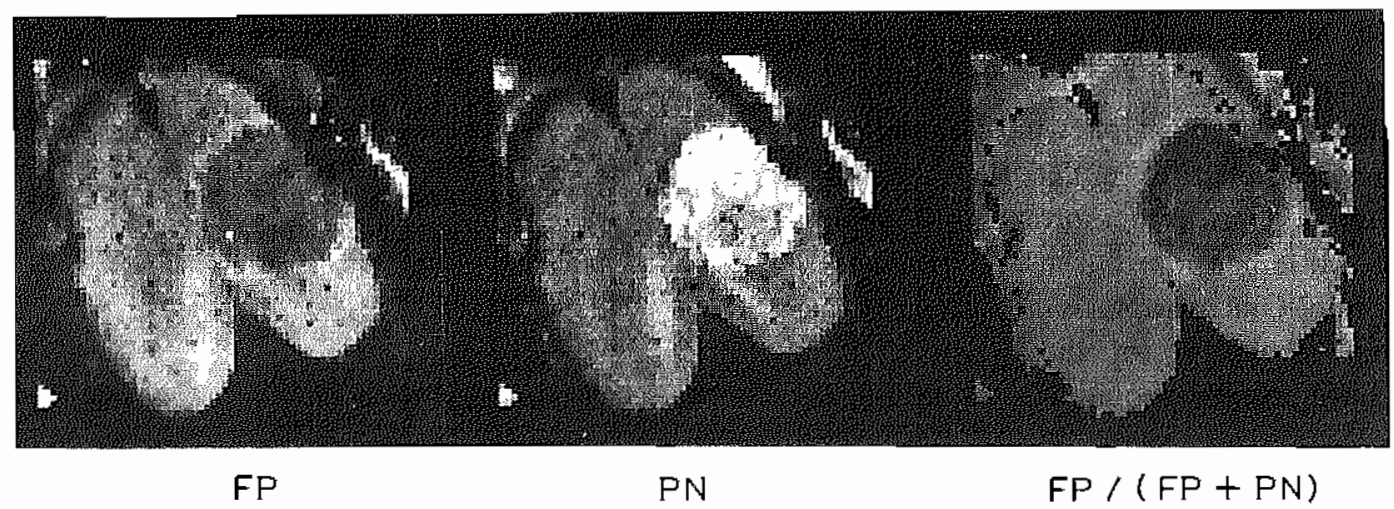

Fig. 1. FP, PN, and MR images of one section of a brain frozen $35 \mathrm{~s}$ after initiation of spreading depression. The plane scanned is parallel to the cortical surface and about $1400, u \mathrm{~m}$ below it. Each image covers an area $1.3 \times 1.3 \mathrm{~cm}$. 


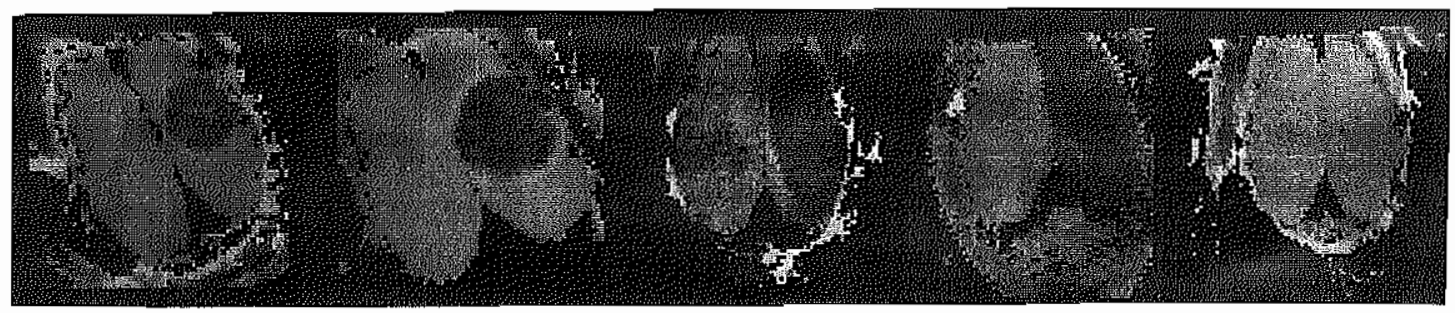

\section{5 secs $\quad 45 \operatorname{secs} \quad 90$ secs $\quad 20$ mins}

Fig. 2. 2-D images of the ratio MR on sections of the cortcx bclow the surface of gerbil brains frozen at diffcrent times after initiation of SD in the right hemisphere. Higher values of MR (corresponding to morc oxidized tissue) are displayed as lighter toncs, lower levcls darker. Field of view of each image is $1.2 \times 1.2 \mathrm{~cm}$.

changes are the same as the changes in signals recorded from brains funnel frozen in control ischemic animals ${ }^{23}$. Thus it seems as if the wave of SD results in the electron carriers of the low-potential end of the mitochondrial electron-transport chain adopting fully reduced condition similar to that found in an anoxic or ischemic cortex.

The 'redox' image (FP/(FP+PN)) shows clearly that the region of reduced tissue is surrounded by an annulus $0.5 \mathrm{~mm}$ wide of tissue in which the mitochondria are more oxidized (white) than in the control hemisphere. While this response can be seen clearly as the bright annulus in the flavoprotein image, the NADH image does not show clearly a dark annulus expected for oxidized mitochondrial pyridine nucleotides. Chance has shown that the NADH and the flavoproteins are very tightly coupled in perfused liver and pigeon heart mitochondria ${ }^{4}$, and there is no evidence to the contrary for brain. Therefore the effect we see is probably duc to hemodynamic effects. A decrease in blood volume in this region will increase both $\mathrm{NADH}$ and flavoprotein signals and will enhance the flavoprotein increase, while hiding an oxidative decrease in the NADH.

\section{Time course of $S D$ in the plane of the cortex}

These images can be interpreted in terms of a radial wave for which a transient period of oxidation is followed by a prolonged period of reduction. Images of the MR ratio in the plane of the cortex of gerbils frozen at different times after initiation of SD (Fig. 2) show that the wave spreads radially from the point of trauma. The velocity is between $2-3 \mathrm{~mm} / \mathrm{min}$, in excellent agreement with other measurcments ${ }^{2,7}$. (Note that the waves of SD in the images of Fig. 2 were initiated by $\mathrm{KCl}$ over a $3 \mathrm{~mm}$ wide region at zero time.) Following the passage of the oxidative-reductive wavefront across the experimental hemisphere of the brain, the hemisphere remains reduced for several minutes, and finally reaches a redox state indistinguishable from the control hemisphere after 1020 min. Since we know the velocity of the wave, we may use a spatial analysis of the wave front to determine the time course. With a velocity $2-3 \mathrm{~mm} / \mathrm{min}$, the spatial resolution of $200 \mu \mathrm{m}$ corresponds to a temporal resolution of 4-6s. The time course of the changes of FP, PN, and MR during spreading depression is shown in Fig. 3. The wavefront of SD consists of a transient period of about $10 \mathrm{~s}$ during which the mitochondrial redox state is oxidized, followed by a period of $20-30$ s of reduction.

\section{$S D$ in three dimensions}

We investigated the spread of the wave of SD through the brain by scanning a series of planes. Fig. 4 shows MR images from such a set of a brain in which SD was initiated using a needle. The images show clearly that the wavefront spreads down through the cortex as well as parallel to the surface. The hippocampus is also reduced as a consequence of the wave of SD initiated there by the needle. The needle was inserted at a slight angle to the center plane of the animal, so that the point of initiation is closer to the mid plane at deeper levels. When SD is initiated by $0.5 \mathrm{M} \mathrm{KCl}$ applied epidurally the wave

PLOT OF FP, PN, AND MR ACROSS A WAVE OF SPREADING DEPRESSION

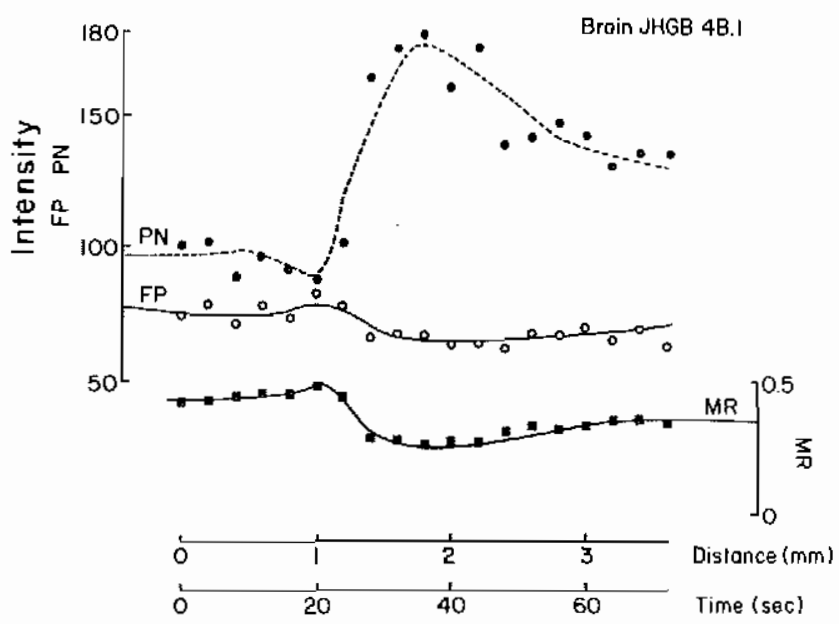

Fig. 3. Plot of FP, PN huorescence value, and of the ratio $M R$ across a brain frozen $45 \mathrm{~s}$ after initiation of SD. The values of FP and PN are the results of digitizing the outpnt of a photomultiplier. and are proportional to the fluorescence intensity. 'the SD was initiated at the right of this plot. The wave front of SD moves to the leit. 
a $\mathrm{b}$

c d

e

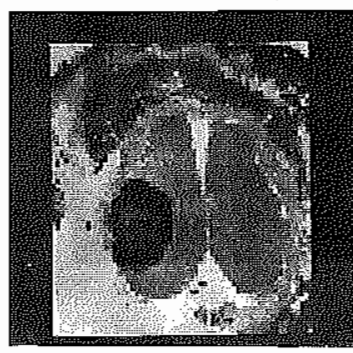

0.5

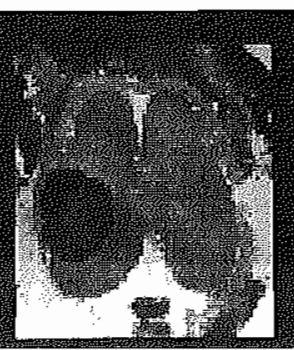

0.8

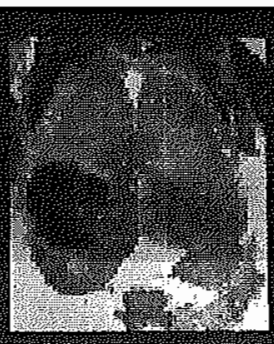

1.1

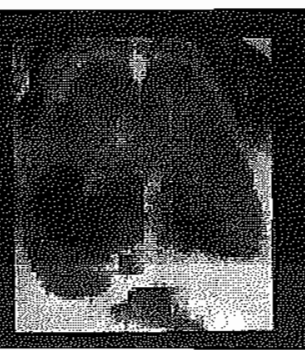

1.4

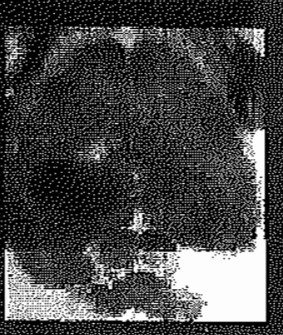

1.7

Depth below cortical surface $(\mathrm{mm})$

Fig, 4. 2-D images of the redox ratio MR at different depths in a gerbil brain frozen 45 s after initiation of SD using a needle. Field of view of each image is $1.3 \times 1.3 \mathrm{~cm}$.

spreads throughout the cortex but does not pass to morphologically distinct regions such as the hippocampus.

\section{Reflectance measurements}

We complemented these fluorescence studies with reflectance spectroscopy to evaluate the state of reduction of mitochondrial cytochromes ${ }^{1}$. Reflectance spectra in the wavelength range of $500-650 \mathrm{~nm}$ were recorded from 4 different regions of a brain frozen $40 \mathrm{~s}$ after the initiation of SD (see Fig. 5A): the regions chosen were 1, the most reduced area of the SD wave, and control areas on the ipsi - and contralateral sides of the brain locations 2,3 and 4 . The spatial resolution of the spectrophotometer was $3 \mathrm{~mm}$, which was not sufficient to record the initial oxidative phase of the wave. Difference spectra

A

\section{Reflectance Specira of Frozen Gerbil} Cerebral Cortex

The brain was funnel frazen $45 \mathrm{sec}$ ofter the initiation of spreading depression.

A Fluorescence images of the frozen corlex

$\mathbb{B}$ Difference spectra between areos $a, 1-3 ; b, 4-2$,

$\mathrm{c}, \mathrm{I}-2 ; \mathrm{d}, 3-2$. Reference $630 \mathrm{~nm}$.

FP
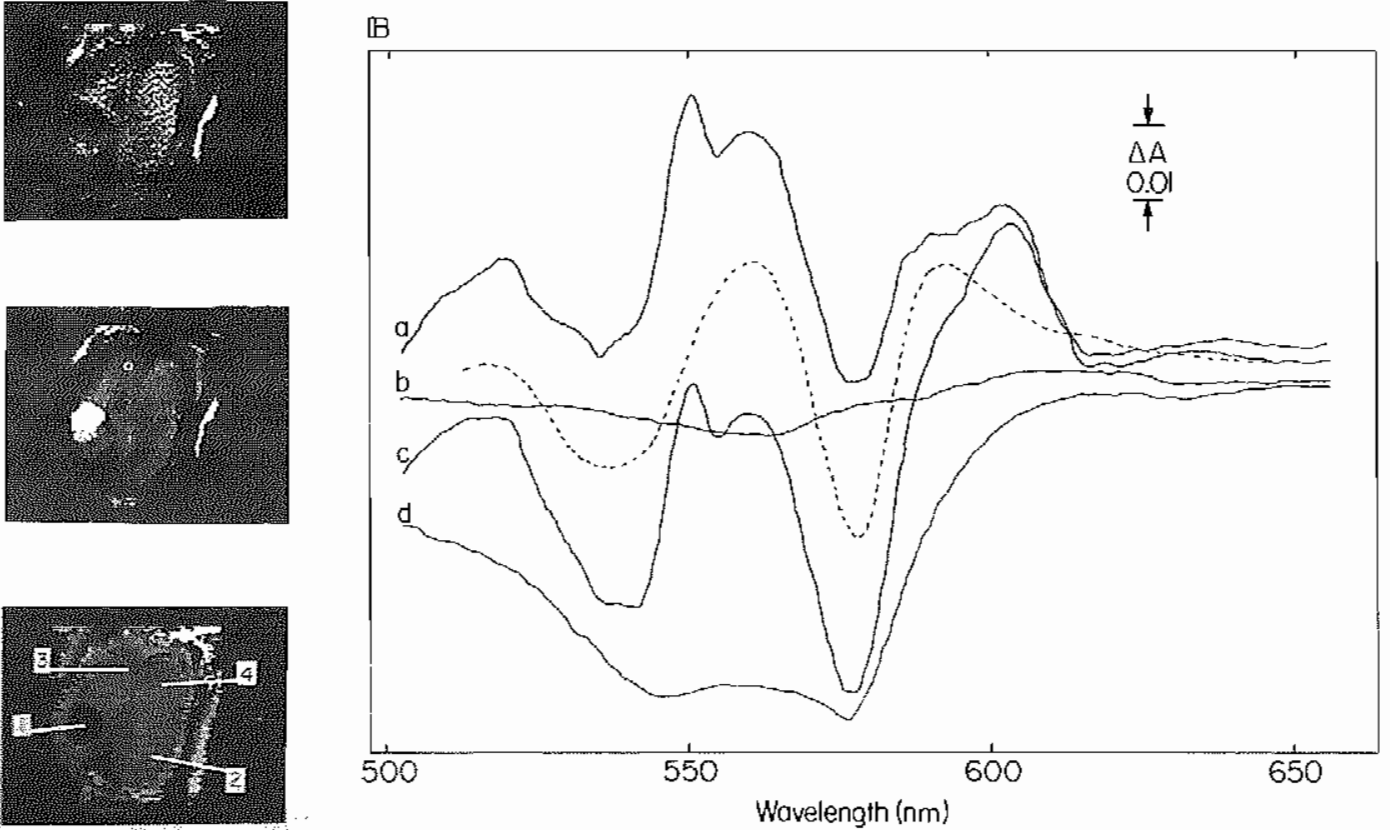

Frg. 5. A: morescence intisges from abrain during SD, 4 arcas are indicated; the region of tissue reduction during SD and 3 control arcas. $\mathrm{B}$ - difference reflection spectre from chenerent regions of a gerbil brain frozen during SD, (a) wave of SD - control on ipsilateral hemisphere; b two control areas. both od the contralateral hemisplere; (c) wave of SD - control region at equivalent position on contralateral hessisphere; (d) difference berween control areas at similar positions on ipsi- and contralateral hemispheres. Dotted line, difference spectrum of deoxy-oxyhemoglobin. 
between the various regions are shown in Fig. 5B and are compared with the difference spectrum of reduced oxy-hemoglobin obtained from frozen gerbil blood. Traces a and $\mathrm{c}$ both compare the region of SD with control areas and have the form of the difference spectrum for hemoglobin on which are superimposed peaks at 550 and $605 \mathrm{~nm}$ of reduced cytochromes $a a 3$ and $c$. Thus, relative to the control regions, the reduced part of the wave of SD is characterized by increased concentration of reduced cytochromes aa 3 and $c$, of reduced pyridine nucleotide and flavoprotein, and of deoxyhcmoglobin. Traces $b$ and $d$ compare the differences between the various control regions of the brain: trace $b$ shows that two regions of the same hemisphere are very similar, while trace d, which compares control areas on the two hemispheres, seems to be a mixture of the oxyhemoglobin and deoxyhemoglobin traces. This curve indicates that there is no difference in the redox state of the cytochromes between the unaffected areas of the two hemisphere of the brain. However, the data suggest that there are hemodynamic effects of decreased blood volume and decreased hemoglobin oxygenation between the control areas of the two hemispheres. This may reflect different hemodynamic conditions in the exposed, and the non-exposed hemispheres

\section{DICUSSION}

The effect of the cortical spreading depression (SD) of Leao in terms of the redox state of the brain mitochondria has been studied in 3 dimensions using a computer linked light-guide scanner to look at the mitochondrial redox state. By using funnel freezing to quench the metabolism of the brains at different periods after the initiation of SD, it has been possible to study the propagation of the wave in 3 dimensions with a spatial ressolution of $200 \mu \mathrm{m}$. The wave of SD is seen to travel through the cortex with a speed of $2-3 \mathrm{~mm} / \mathrm{min}$ in agreement with the speed determined from other measurements ${ }^{2}$. The wave of SD easily spreads through the part of the brain in which it is initiated, but does not readily cross distinct morphological boundaries; a wave of SD initiated into the cortex will not cross into tbe hippocampus, although it may be initiated there ab initio be a deeply inserted needle. We have not yet seen the SD spread from one hemisphere of a gerbil to the other as Leao reported in the rabbit ${ }^{17}$, or as Csiba et al. reported for the $\mathrm{rat}^{7}$.

Studies of extracellular potassium ion concentration ${ }^{9,24}$ show that the wave of $\mathrm{SD}$ is accompanied by a large increase in the extracellular potassium, which must then be pumped back into the cells. Glucose consumption is increased significantly ${ }^{8,30}$. Such a work load on the cell would be expected to raise the ADP level in the cell and switch the mitochondria from their resting state to the more active state 3 of Chance and Williams ${ }^{5}$ with a concomitant oxidation of the NADH and flavoproteins ${ }^{24}$. Rosenthal and Somjen ${ }^{29}$, and Mayevsky et al. ${ }^{21.24}$, do observe what they term a state 4-3 transition at this time, while Haselgrove et al. ${ }^{10}$ report that the electrical changes precede the changes in redox levels.

The first effect of SD that we see on the mitochondria of brain is an increase in the oxidative state accompanied by a drop in blood volume. Such decreases in brain blood volume have also been reported by Mayevsky ${ }^{20.22}$. It is not yet clear what hemodynanic effects give rise to this phenomenon. Van Harreveld and Stamm ${ }^{32}$ deduced that there is a vasoconstriction of pial vessels early in the course of SD, although Wahl et al. ${ }^{33}$ could see no such effect by direct observation. Gjedde et al. ${ }^{8}$ measured a slight decrease in blood flow at this stage althongh Lauritzen did not ${ }^{14}$. It is possible that the spatial resolution of Lauritzen's techniqne $(5-15 \mathrm{~mm})$ was too large to detect a transient change occurring in a $1 / 2$ $\mathrm{mm}$-wide annulus such as we see. Nonetheless, regardless of the cause of the initial hemodynamic effects, the ratio data show clearly and consistently that the initial response to SD is that the brain tissue does become oxidized.

The transient oxidative phase of the wave of SD is followed by a prolonged period of reduction in which the mitochondria may be nearly completely reduced for a period of $30-40 \mathrm{~s}$. During this period of maximal reduction, the reflectance spectra indicate that the cytochromes $a a 3$ and $c$ are largely reduced, and the hemoglobin is deoxygenated. The simultaneous reduction of the cytochromes and the NADH/flavoprotein components of the mitochondria is typical of the mitochondria being in state 5: viz., the degree of oxidation is limited by the supply of oxygen. Presumably, the energy demands on the brain cells are so high that the mitochondria are required to funtion at a rate well in cxcess of the available oxygen supply, even though this second phase of SD is associated with a two-fold increase in blood flow ${ }^{8,9}$. Indeed, previous workers ${ }^{7.8}$ have demonstrated that SD is accompanied by anaerobic glycolysis.

Previous studies by Mayevsky ${ }^{20,22}$ have shown that a lightly anesthetized or awake animal responds to SD with only an oxidative phase, but that more heavily anesthetized animals do show a biphasic (oxidized-reduced) response. Indeed the other studies which have found an anaerobic response using different techniques have used animals with similar anesthetic states to ours ${ }^{7.8}$. It is possible that the deep pentobarbital anesthesia ${ }^{25}$ may in part be responsible for the inability of the oxygen supply to keep up with the mitochondrial demand. 
The third and final phase of the wave of SD is a slow recovery lasting from 5 to 20 min during which the redox state of the whole cortex slowly returns to that of the control hemisphere recovering from lactate acidosis. This recovery time is similar to that reported by Leao ${ }^{16}$ for the recovery of the spontaneous electrical activity in the rabbit.

The present studies indicate that in the anesthetized animal, the largest change in signal is that of a reduction of the redox state of the mitochondria putting them in state 4 or 5 . Since the redox state of the NAD-NADH and of flavoproteins is similar in states 4 and 5, the

\section{REFERENCES}

1 Bashford, C.L., Barlow, C.G., Chance, C., Haselgrove, J.C. and Sorge, J.R., Optical measurements of oxygen delivery and consumption in gerbil cerebral cortex, Am. J. Physiol., 242 (1982) C265-271.

2 Bures, J., Buresova, O. and Krivanek, J., The mechanism and applications of Leno's sprending depression of electroencephalographic activity, Aeademic Press, New York, 1974, pp 69-70.

3 Chance, B. and Graham, N., A rapid scanning dual wavelength spectrophotomctcr, Rev. Sci. Instr., 42 (1975) 941-945.

4 Chance, B., Schoener, B., Oshino, R., Itshak, F. and Nakase, Y., Oxidation-reduetion ratio studics in frecze-trapped samples, J. Biol. Chem., 254 (1979) 4764-4771.

5 Chance, B. and Williams, G.R., Respiratory enzymes in oxidative phosphorylation, J. Biol. Chem., 217 (1955) 409-427.

6 Collewijn, H. and Van Harrcveld, A., Membrane potential of cerebral cortical cells during spreading depression and asphyxia, Exp. Neurol., 156 (1966) 425-436.

7 Csiba, L., Paschen, W. and Mies, G., Regional changes in tissue $\mathrm{pH}$ and glucose content during cortical spreading depression in rat brain, Brain Research, 336 (1985) 167-170.

8 Gjedde, A., Hansen, A.J. and Quistorff, B., Blood-brain glncose transfer in spreading depression, J. Neurochem., 37(4) (1981) 807-812.

9 Hansen, A.J. Quistorfr, B. and Gjedde, A., Rclationship between local changes in cortical blood flow and extracellular $\mathrm{K}$ during spreading depression, Acta. Physiol. Scand., 109 (1980) $1-6$.

10 Haselgrove, J., Barlow, C, Eleff, E., Chance, B. and Lcbordais, S., Corrclation of clectrical signals and initochondrial redox state during spreading depression. in A.G.B. Kovach, M. Kessler and I.A. Silver (Eds.), Adv. Physiol. Sci. Vol. 25, Oxygen Transporr to Tissue, Pergamon, 1980, p. 25.

11 Hassinen, I. and Chance. B.. Oxidation-reduction properties of the mitochondrial navoprotein chain, Biochem. Biophys. Res. Commun., 31 (1968) 895-900.

12 Krivanck, J., Some metabolic changes accompanying Leao's spreading cortical depression in the rar, J. Neurochemistry, 6 (1961) 183-189.

13 Krivanek, J. and Fifkova, E., The value of ultramicro-analysis of lactic acid in tracing the penetration of teao's corrical spreading depression to subcortical arcas. J. Neurol. Sci., 2 (1965) $385-392$.

114 Lauritzen, M., Regional cerebral blood how during cortical spreading depression in rat brain: increased reactive hyperfusion in low-flow states, Acta Neurol. Scand., 75 (1987) 1-8.

15 Leao, A.A.P., Spreading depression of activity in the cerebral cortex. J. Neurophysiol. 7 (1944) 359-390.

16 Leao, A.A.P., Further observations on the spreading depression of activity in the cerebral cortex, J. Ncurophysiol., 10 (1947) 409-414.

17 Leao, A.A.P. and Morison, R.S., Propagation of spreading present data indicated that a resting. anesthetized brain may be in a more oxidized state much closer to state 3 than state 4 (say state 3.3 ). The same conclusion was reached by Mayevsky ${ }^{19}$ when working with awake animals. The fluorescence and reflectance data may then be all interpreted if the effect of SD is to increase energy output enormously. The mitochondria which start in state 3.3 move to state 3 by the increased levels of ADP, then go to state 5 when the supply of oxygen can not keep up with the demand, and finally return to their resting state.

Acknowledgements. Supporled in part by NIH Grant NS22881

cortical depression, J. Neurophysol, 8 (1945) 33-45.

18 Marshall, W.H., Spreading cortical depression of Leao. Physiol. Rev., 39 (1959) 239-279.

19 Mayevsky, A., Brain energy metabolism of the conscious rat exposed to various physiological and pathological situations, Brain Research, 113 (1976) 327-338.

20 Mayevsky, A. and Chance, B., Intracellular oxidation-rcduction state measured in situ by a multi-channel fiber-optic surface fluorometcr, Science, 217 (1982) 537-540.

2t Mayevsky, A. and Chance, B., Metabolie responses of the awake cerebral cortcx to anoxia, hypoxia, spreading depression, and cpiletiform activity, Brain Research, 98 (1975) 149-165.

22 Mayevsky, A., Lebordais, S. and Chance, B., The interrclation between brain $\mathrm{PO}_{2}$ and NADH oxidation-reduction state in the gerbil, J. Neurosci. Res., 5 (1980) 173-182.

23 Mayevsky, A., Kaplan, H., Haveri, J., Hasclgrove. J. and Chance, B., 'threc-dimensional Inetabolic mapping of the freczc-trapped brain: effects of ishemia in the mongolian gerbil. Brain Research, 367 (1986) 63-72.

24 Mayevsky, A., Zcuthan, T. and Chance, B., Measurements of extracellular potassinm, ECoG, and pyridine nuelcotide lcvels during cortical sprcading depression in rats, Brain Research, 76 (1974) 347-349.

25 Nilsson, B. and Siesjö, B., The effect of phenobarbitone anaesthesia on blood llow and oxygen consuinption in the brain, Acta, Anaesth. Scand. Suppl., 57 (1975) 18-24.

26 O'Connor, M.J., Welsh, F., Komarnicky, L., Davis, 1, Stevens, J., Lewis, D. and Herman, C., Oxygen and physiological function. In F.F. Jobsis (Ed.), Professional Information Library, Dallas, Tcxas, 1976, pp. 90-99.

27 Ponten, U., Ratcheson, R.A., Salford, L.G. and Siesjö, B., Optimal freezing conditions for cerebral metabolites in rats, $J$. Neurochem., 21 (1973) 1127-1138.

28 Quistorfr, B., Haselgrove, J.C. and Chance, B., High spatial resolution read-out of 3-D-metabolic organ structure. An automatcd, low temperature redox ralio scanning instrument, Anal. Biochem., 148 (1985) 389-400.

29 Rosenthal, M. and Somjen, G., Spreading depression, sustained potential shifts, and Inetabolic aclivity of cerebral cortex of cats, J. Neurophysiol., 36 (1973) 739-749.

30 Shinohara, M., Dollinger, B., Brown, G., Rappaport, S. and Sokoloff, L., Cerebral glucose utilization: Jocal changes during and after recovery from spreading cortical depression, Science, 203 (1979) $188-190$.

31 Van Harreveld, A. and Ochs, S., Electrical and vascular concomitants of spreading depression, Am. J. Physiol., 189 (1957) $159-166$.

32 Van Harreveld, A. and Stamm, J.S., Vascular concomitants of sprcading cortical depression. J. Neurophysiol., 15 (1952) $487-496$.

33 Wahl, M., Lanritzen, M. and Schilling, L., Change of cerebrovascular reaetivity after cortical spreading depression in cats and rats, Brain Research, 411 (1987) 72-80. 